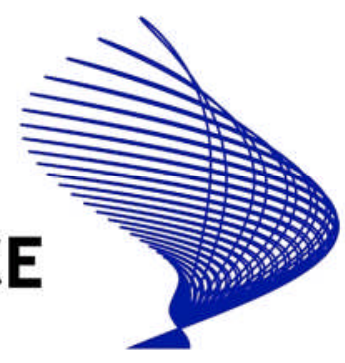

NORFACE MIGRATION Discussion Paper No. 2013-03

\title{
Measuring Cultural Diversity and its Impact on Innovation: Longitudinal Evidence from Dutch firms
}

Ceren Ozgen, Peter Nijkamp and Jacques Poot 


\title{
Measuring Cultural Diversity and its Impact on Innovation: Longitudinal Evidence from Dutch firms*
}

\author{
Ceren Ozgen ${ }^{a}$, Peter Nijkamp ${ }^{b}$ and Jacques Poot ${ }^{c}$
}

\begin{abstract}
To investigate econometrically whether cultural diversity of a firm's employees boosts innovation, we create a unique linked employer-employee dataset that combines data from two innovation surveys in The Netherlands with administrative and tax data. We calculate three distinct measures of diversity. We find that firms that employ fewer foreign workers are generally more innovative, but that diversity among a firm's foreign workers is positively associated with innovation activity. The positive impact of diversity on product or process innovations is greater among firms in knowledgeintensive sectors and in internationally-oriented sectors. The impact is robust to accounting for endogeneity of foreign employment.
\end{abstract}

JEL code: D22, F22, 031

Keywords: immigration, innovation, cultural diversity, knowledge spillovers, linked administrative and survey data

2 January 2013

\footnotetext{
* This research is part of the Migrant Diversity and Regional Disparity in Europe (MIDI-REDIE) project, funded by the NORFACE research programme Migration in Europe - Social, Economic, Cultural and Policy Dynamics. Earlier versions of this paper have been presented at the 50th European Congress of the Regional Science Association International, Barcelona, Spain, August 30-September 3, 2011, and at the International Workshop on Economic Impacts of Immigration and Population Diversity, National Institute of Demographic and Economic Analysis (NIDEA), University of Waikato, Hamilton, New Zealand, April 11-13, 2012.

Corresponding Author: Ceren Ozgen (c.ozgen@vu.nl)

a,b Department of Spatial Economics, VU University Amsterdam, De Boelelaan 1105, 1081 HV Amsterdam, The Netherlands. ${ }^{c}$ National Institute of Demographic and Economic Analysis, University of Waikato, Private Bag 3105, Hamilton 3240, New Zealand.
} 


\section{Introduction}

A recent strand of the migration literature has focused on the association between innovation and the presence of foreign workers. There are several ways in which culturally diverse foreign workers can impact on innovation. Some of these are positive, while others are negative (for a review, see e.g. Alesina and La Ferrara, 2005). A positive impact could be due to immigrants being positively selfselected in terms of their abilities and attitudes, for example, in terms of entrepreneurship and risk taking. Secondly, immigrant recruitment policies of developed countries increasingly favour highly skilled young migrants. Thirdly, immigrants bring to the workplace different ideas and perspectives from their cultural backgrounds. Fourthly, foreign workers can facilitate trade with their home countries and/or encourage the production of ethnic goods and services in host countries. Finally, immigrants often exhibit high labour mobility, particularly in their early years in the host country. This speeds up the inter-firm dissemination of new ideas.

On the negative side, cultural diversity can impede communication between workers, or lower levels of trust within or between firms. Secondly, discrimination and non-transferability of skills, or nonrecognition of qualifications, can be barriers to free exchange of ideas and the accumulation of new knowledge. Thirdly, co-ethnic networks can lead to spatial or occupational segregation and clustering of migrant groups, which may also impede the contribution of immigrants to firm innovation.

Given such a mixture of positive and negative effects, it is clear that the overall impact of immigration on innovation is largely an empirical matter. In this context, various approaches are possible. The first is to test whether there is more innovation, ceteris paribus, in geographical areas (cities, regions) that are more culturally diverse. Several empirical case studies do suggest that agglomerations with greater cultural diversity among their foreign born residents have higher levels of innovation (Ottaviano and Peri, 2006; Suedekum et al., 2009; Niebuhr, 2010; Ozgen et al., 2012). On the other hand, a larger share of immigrants in the labour force is often associated with lower levels of innovation, particularly when the issue of endogeneity of migrant settlement (with migrants predominantly settling in larger agglomerations that are more innovative) is taken into account (Ozgen et al., 2012).

The second approach to identifying benefits of immigration for innovation is to focus on foreign knowledge workers themselves and to compare the innovation activity of these workers, e.g. the extent to which they generate patents, with those of native-born knowledge workers. The evidence is fairly conclusive that host countries benefit from attracting highly able knowledge workers from abroad (e.g., Zucker and Darby, 2007; Hunt and Gauthier-Loiselle, 2010; Kerr, 2010; Kerr and Lincoln, 2010).

The third approach is to consider the ethnic composition of staff at the workplace level within firms. This is arguably the toughest test of spillover benefits of cultural diversity on co-workers, since it attempts to empirically identify localised spillover benefits of foreign workers who mostly only represent a small minority of the employees. At this level, the evidence to date is less conclusive. Ozgen et al. (2011) find - using micro-level cross-sectional data in The Netherlands - that firms with a greater share of foreign workers are on average less innovative, but that cultural diversity among a firm's foreign employees enhances innovation. Similar evidence has been found by Niebuhr and Peters (2012) for Germany, by Parotta et al. (2011) for Denmark, and by Lee and Nathan (2010) for firms in London. However, using similar data as Ozgen et al. (2011) utilize for The Netherlands, 
$\varnothing$ stergaard et al. (2011) find no significant effect of ethnic diversity on innovation at the firm level in Denmark. Moreover, Maré et al. (2011) find no evidence that cultural diversity of New Zealand firms boosts innovation.

Managers themselves often attest to a diverse workforce being crucial for encouraging different perspectives and ideas that drive innovation (e.g. Forbes, 2011). However, the evidence is not conclusive that management practices that encourage ethnic diversity have a positive impact on a firm's performance. Considering explicitly how teams perform within firms, a meta-analysis by Bell et al. (2011) concludes that ethnic diversity negatively impacts on team performance. On the other hand, taking the very specific case of sports teams, Alvarez et al. (2011) provide evidence that the recruitment of foreign players in European basketball teams benefits the overall performance of these teams. In any case, various measures are suggested in the literature to mitigate the possible negative impacts of diversity (Ely and Thomas, 2001). These varying results seem to point out that the positive impacts of diversity are likely to emerge in special context.

In this paper we extend the analysis of Ozgen et al. (2011) in four ways. Firstly, we are able to construct a much larger data set on firm level innovation than in our previous paper. This is achieved by combining the results of two successive innovation surveys (in 2002 and 2006, respectively) with migrant characteristics and by imputing a skill level to migrants and the native born based on their annual wages obtained from tax registers, rather than by restricting the observations to those who were included in the Dutch labour force survey and of whom, therefore, the skill level was explicitly recorded. Secondly, the larger data set permits us to exploit a panel structure in which we can account for unobserved time-invariant heterogeneity of firms in the standard way. Thirdly, we introduce a wider range of distinct measures of diversity than has hitherto been the case. By doing so, we are able to decompose the concept of diversity, and show now how the composition of labour with respect to diversity impacts on innovation. Finally, we focus on specific sectors and types of firms through disaggregating results according to market orientation of the firm (domestic versus international), industry and the type of innovation (general, product or process).

We find that firms that employ many foreign workers are generally less innovative, but that diversity among foreign workers is positively associated with innovation activity. This effect is greater among firms in knowledge-intensive sectors and in internationally-oriented sectors, and is robust to accounting for endogeneity of foreign employment. We conclude that the recruitment of high-skilled talent, which is a cornerstone of current immigration policy in many developed countries, is particularly beneficial for innovation when such immigrants represent a variety of cultural backgrounds.

The next section provides a brief discussion of the ways in which immigrants and cultural diversity among foreign born or second-generation ethnic workers may influence innovation. Section 3 describes the econometric model, while section 4 outlines how the dataset was constructed and how cultural diversity has been measured. Section 5 discusses the results of the regression analysis, while section 6 offers concluding remarks. 


\section{Migrant Diversity and the Determinants of Innovation}

Innovation is the process by which firms create better products, processes, services, technologies, or ideas. There is a vast literature that discusses the determinants of innovation, starting with a seminal contribution by Acs and Audretsch (1988) and a review by Dosi (1988). Innovation can be thought of as the output of a knowledge production function, with major inputs consisting of the funds devoted to R\&D, combined with the appropriate capital and skilled labour. More generally, theoretical modelling and empirical evidence to date suggests that available indicators of innovation activity at the firm level are linked to firm size, market structure, R\&D investment, gross fixed capital formation, the availability and composition of skilled labour, the nature of the industry, the domestic and foreign networks of firm owners and employees, features of the area in which the firm is located, and institutional factors.

Generally, a firm will employ workers of many types defined by skills, experience and occupation. Employment plays an important role in innovation, as technological advances come from things that people do (Romer, 1990). Standard neoclassical labour demand theory shows that the demand for each type of worker is determined by the demand for output, the wages to be paid, the production technology and the related extent of substitutability or complementarity between the different types of labour. Even without spillover benefits from cultural diversity and with workers of different cultural backgrounds for given skill levels being perfect substitutes in production, the firm's labour force may exhibit a cultural mix that reflects the cultural composition of the workforce in the local labour market. For reasons linked with networks, past migratory behaviour, international airport locations and job opportunities, migrants - and particularly skilled ones - are disproportionally attracted to large metropolitan areas (e.g., Poot et al. 2008). Because such metropolitan areas are also the areas where much innovation activity takes place (e.g. Lobo and Strumsky, 2008; Audretsch and Feldman, 2004), a spatial correlation between cultural diversity and innovation may be observed, even when there is no causal link.

A positive causal link from diversity to innovation may nonetheless exist for various reasons. The first is that firm expansion may be constrained by local scarcity of highly skilled and specialised labour, in which case recruitment from abroad may essential (Beaverstock and Hall, 2012). The growth in knowledge-intensive industries has led to global competition for talent, which is complementary to locally available skills and can therefore contribute to firm expansion and the associated innovation activity.

Besides these direct effects of diversity on innovation, there are also likely to be knowledge spillovers from the employment of workers with different cultural backgrounds. Similarly, successful migrant entrepreneurship can also spill over to host country entrepreneurs (Jaeger and Duleep, 2010). Moreover, with different perspectives and approaches to problem solving, migrants may contribute to better decision making (Page, 2007). Of course, the effectiveness of such spillovers are contingent on production conditions, such as the organisational culture, labour market structure and institutions that jointly determine the receptivity of foreign knowledge at the destination (Jones and Romer, 2010).

In contrast to these positive effects, there are also negative effects of cultural diversity that were already briefly alluded to in the introduction. The first point is that the lower reservation wages of immigrants may have a negative impact on long-run growth, when the availability of cheaper labour makes it rational for firms to adopt more labour-intensive production technologies and thereby 
discourage investment in new and technologically superior machines and equipment. This effect would operate particularly with respect to the employment of lower skilled employees. High skilled immigrants are likely to exhibit complementarity with new technology in production.

Secondly, cultural diversity at the workplace can create communication problems, either simply due to linguistic difficulties but also due to misunderstandings associated with differences in tastes, norms and values between immigrants and the native born. Such misunderstandings could negatively impact on the effectiveness of day to day interactions and the productivity of team work. Heterogeneity in norms and values may also lead to distrust or even outright conflict. In any case, decision making in a diverse workplace may be more time consuming and therefore more costly. Cultural diversity of staff may also trigger discrimination of minority groups, which in turn lowers the productivity of the firm.

Migrants are generally young and have a high degree of labour mobility. While this 'greases the wheels' of the local labour market (Borjas, 2001), it also implies that at the workplace level immigrants often have less job tenure and therefore less job-specific training. If they contemplate repeated migration, they may also exhibit less commitment to the firm. Such phenomena could negatively impact on knowledge spillovers.

A further consequence of growing ethnic diversity is that it tends to lead to greater geographical clustering and segregation (see e.g. Cutler et al. 2008). While ethnic precincts may have positive urban consumption externalities, it may also limit the supply of foreign workers outside the precincts or increase commuting distances of ethnic workers employed elsewhere in the city, with associated increased employment costs.

We have identified a range of positive and negative impacts of cultural diversity on innovation and firm performance. The overall impact remains an open question, both in terms of firm profitability and in terms of general welfare. Some studies suggest an inverted U-shape relationship between diversity and economic performance (see e.g. de Graaff and Nijkamp, 2010), leading to the notion of optimal diversity. The evidence presented in this paper suggests that at the firm level, and for the levels of immigration observed in the last decade, the impact of diversity on innovation at the firm level has been positive, but with insufficient within-firm variation over the 2002-2006 period to detect it in firm fixed effects models. However, a wide range of random effects models find a significantly positive impact of diversity, particularly in the case of high skilled migrants in knowledge-intensive sectors. The firm level evidence presented here complements the evidence of a positive impact of diversity on innovation at the city level already mentioned in the introductory section. The latter points to broader spillover benefits in consumption, production and endogenous institutions, such as had already been highlighted by Jacobs (1969).

\section{Specification of the Econometric Model}

To estimate the impact of foreign workers on innovation we utilize a linear probability model estimated with a two-wave panel data set. In our model, whether or not a firm reports any innovation is a function of various firm characteristics, employee characteristics and characteristics of the local economy (for summary statistics see Table 1). Given a large sample of data and the incidence of innovation being relatively high, we estimate a linear probability model in which the 
coefficients can be directly interpreted as marginal effects (e.g. Angrist, 2001). In any case, logit estimation revealed highly similar results. ${ }^{1}$ The Dutch community innovation surveys (CIS) does not provide patent applications or patents granted, or other quantitative measures of innovation. Instead, the response variable is binary and reports whether a firm introduced any innovation, new products and/or services, or new processes within the past two years. ${ }^{2}$ We estimate the following specification:

$$
\begin{array}{r}
\operatorname{Pr}(\text { Innovate })_{i t}=f(\text { Firms characteristics, Employee characteristics, } \\
\text { Area characteristics })_{i t}+v_{i}+\delta_{t}+\varepsilon_{i t},
\end{array}
$$

in which $\operatorname{Pr}$ (Innovate) it $_{\text {it }}$ a dummy variable that measures firm $i$ 's self-reported innovation (yes or no) in wave $t$, with $\varepsilon_{i t}$ a random error term and $v_{i}$ and $\delta_{t}$ random or fixed firm effects and time effects, respectively. The panel data available for this paper consist of two waves. The econometric specification includes the determinants of innovation suggested by the literature. The independent variables can be listed in four groups. The first is a set of firm characteristics; firm size accounts for firms' fixed and capital assets. Secondly, obstacles to firm profitability and growth, such as a lack of personnel and finance constraints, may force a firm to seek innovative solutions. In the recent innovation literature the importance of so-called soft factors are emphasized as an indication of firms' adaptation to its external environment (Jensen et al., 2007), thus firms' openness to change is also considered. Firms are more likely to employ foreign workers if they are more export-oriented and internationally connected. We control therefore for the international orientation of firms in the econometric modelling. In models where the full sample of firms is used, we include 22 macro-sector fixed effects ${ }^{3}$; in others we adopt a panel model with firm fixed effects.

The second group of variables is a set of employee characteristics that includes the demographic and occupational characteristics of the workers. Cultural background is defined by country of birth. Clearly, country of birth is only an approximate measure of culture but has the advantage that, unlike measures of nationality, it is constant and objective. By excluding the descendants of migrants in the host country population, we adopt a narrow measure of diversity. If cultural diversity effects are found with our data, they are also expected to be present in broader measures of cultural or ethnic diversity. We focus specifically on the demographic and occupational characteristics of foreign born employees. To test whether firms employing young migrants are more innovative (e.g. Poot, 2008), the age composition of a firm's foreign workforce is included and measured by the share of 25-44 years old in total foreign employment per firm. Similarly, we consider the share of high skilled workers in total foreign employment. For both waves of the panel, all of the employee variables are lagged by two years to diminish the possibility of reverse causality (in which innovative firms are more likely to recruit foreign workers). In any case, we conduct also IV estimations.

The third group of variables relates to the area in which the firm is located and specifically to urban economic agglomeration and its possible impacts on firms. The measures used in the analysis are

\footnotetext{
${ }^{1}$ The results are available from the corresponding author upon request.

${ }^{2}$ The exact definitions are as follows. A product innovation is the market introduction of a new good or service or a significantly improved good or service with respect to its capabilities, such as improved software, user friendliness, components or sub-systems. A process innovation is the implementation of a new or significantly improved production process, distribution method, or support activity for a firm's goods or services.

${ }^{3}$ The 22 Sector fixed effects match with the 2-digit international industrial NACE classification.
} 
market structure (the ratio of firms over jobs per COROP region ${ }^{4}$ ) and a density variable (the number of firms per municipality). The former measures the extent of local competition while the latter measures the extent of agglomeration.

The fourth group of measures refer to the diversity of employees of a firm. There is no one way in measuring such diversity. The selection of a diversity measure depends on the research question and the nature of the data (see Nijkamp and Poot, 2012). We aim to disentangle different aspects of diversity; for example a sample can be very diverse yet have significant clustering with respect to same groups. Therefore, we scrutinize three aspects of a diverse population; $i$ ) an aggregate measure of the diversity of the whole population; ii) homogeneity of the foreign workers; iii) richness of the foreign composition.

First, we utilize an index of diversity which is an aggregate measure for the composition of the total workforce of a firm. This is referred to as the Simpson index and the natives are also included in calculating this index. The index is calculated as follows:

$$
\operatorname{Simpson}_{i t}=1-\left\{\sum_{b=1}^{B} \frac{s_{b i t}\left(s_{b i t}-1\right)}{L_{i t}\left(L_{i t}-1\right)}\right\}
$$

in which $s_{b i t}$ is the total number of employees with birthplace $b(b=1,2, \ldots, B)$, in employment of firm $i$ $L_{i t}(i=1, \ldots, N)$ at time $t$. It has the advantage of being scale independent. The diversity of a firm increases with an increasing value of the index. The index value can range between 0 (all employees originate from the same country) and which approaches 1 when the firm is large and there are an equal number of employees originating from different countries. ${ }^{5}$ However, the Simpson index is insensitive to the addition of rare groups to the sample, and obviously, abundant groups get more weight. This measure has the advantage of accounting for the relative shares of each group in the overall population of a firm. However, because natives are by far the most dominant group in firm's workforce, it can also be regarded as a measure of Dutchness with our data. The higher the share of natives, the lower the Simpson index.

The second diversity measure focuses on exposure to own kind, i.e. the degree of potential contact among foreigner workers. This measure of diversity is a co-location index which shows to what extent a foreigner has been exposed, within the firm, to other foreigners who share his/her country of birth. The index is calculated as follows:

$$
\operatorname{Coloc}_{i t}=\left\{\frac{1}{2} \sum_{l=1}^{F_{i t}} \sum_{\substack{k=1 \\ k \neq l}}^{F_{i t}} I\left(b_{l}=b_{k}\right)\right\} / L_{i t}
$$

where $b_{l}, b_{k}\left(b_{l}, b_{k}=1, \ldots, B\right)$ indicates the birthplace of a foreign employee $l, k\left(l, k=1, \ldots, F_{i t}\right)$ in firm $i$ $(i=1, \ldots, N)$ at time $t$, and $I$ stands for the indicator function that takes on the value 1 if the two

\footnotetext{
${ }^{4}$ The COROP division refers to functional regions that are based on the commuting distances in the Netherlands. At the European level, it corresponds to the NUTS 3 level division.

${ }^{5}$ When the number of employees are equally spread across B birthplaces, the value of the index is $L_{i t}(1-1 / B)$ $/\left(L_{i t}-1\right)$.
} 
employees $l$ and $k$ within the firm have the same country of birth and zero otherwise. The colocation index takes on the value zero if the firm has no two foreign workers sharing the same country of birth, or when the firm is composed of natives only. The index value is equal to the sum of the number of coincidences per firm divided by the total number of employees, $L_{i t}$, in firm $i$. If all $F_{i t}$ foreign workers were born in the same country $\operatorname{Coloc}_{i t}$ is $1 / 2\left[\left(\mathrm{~F}_{\mathrm{it}}\left(\mathrm{F}_{\mathrm{it}}-1\right)\right) / \mathrm{L}_{\mathrm{it}}\right]$. It is clear that the larger the value of $\operatorname{Coloc}_{i t}$ is, the higher the homogeneity of foreign employment in firm $i{ }^{6}$

Third, we argue that the richness of the birthplace variety is another important component of a diverse population. If one considers that each country has its own distinct features, the way people think, act, and work will vary with the number of countries represented in each firm. A Nobel Laureate Linus Pauling said: "the best way to have a good idea is to have a lot of ideas" (Uzzi and Dunlap, 2005). Thus, a simple count of the unique number of countries of birth represented in each firm is an alternative measure of diversity at the firm level:

$$
\text { Unique }_{i t}=\sum_{b=1}^{B} U_{b i t}
$$

in which $U_{b i t}$ is a dummy variable that is equal to one when country $b$ is represented in firm $i$ at time $t$ and zero otherwise. With the increasing cultural diversity at the firm level, the value of unique increases. Its value ranges between 1 and $B .^{7}$

The following section describes the creation of the linked employer-employee dataset (LEED) and the sample statistics.

\section{Data and Construction of the Sample}

We combine three confidential high-quality firm/individual level micro-datasets obtained from Statistics Netherlands. The firms in our dataset come from the Community Innovation Surveys $\mathrm{CIS}$ 3.5 (2000-2002) and CIS 4.5 (2004-2006) which provide the anchor of our empirical strategy. The innovations surveys monitor periodically the innovativeness of Dutch firms. The surveys straddle over two years between the time the questionnaires are sent to firms and the results are reported. Each survey provides about 11000 firm observations. ${ }^{8}$ The employee data are retrieved from the Tax Register in the Netherlands (SSB_Banen) which is a census of employees in the Dutch labour market. This dataset covers about 10 million employees, who can be observed multiple times (for more details see Ozgen et al., 2011). Finally, the ethnic and demographic background information of the employees is obtained from the Dutch Municipal Registers (GBA) which provides a census of people living in the Netherlands, with about 16 million observations. Firms are company establishments

\footnotetext{
${ }^{6}$ Accordingly, in our sample, at the very right tail of the distribution for Coloc, most coincidences occur in the Low-skilled business services sector, while on the left tail of the distribution least coincidences occur in Wholesale trade and repair sector.

${ }^{7}$ The number of countries of birth represented in a firm varies between 1 (Netherlands only) and 197.

${ }^{8}$ To create the sample, Statistics Netherlands selects the firms from the General Business Register. Publicsector and NGO-type of activities are excluded. A further selection is based on firm size. Firms employing less than 10 persons are not included in the sample. Firms employing more than 50 persons are all included in the sample, i.e. for such firms the survey is a census. For firms employing 10 to 50 persons, only a fraction is randomly selected into the sample. The size of this fraction depends on the industry and the firm size.
} 
with autonomous production and decision features. Innovation is a binary variable. A firm is an innovator if during the reporting period it has improved a current product (process) and/or produced a new product (process). If the firm has cancelled a previous innovation, it is also considered an innovator in the current period.

To create our sample we followed a three-step data linking procedure. First, the two cross-sections of $\mathrm{CIS}$ are linked to create a balanced panel of firms that can be followed over the four years. Secondly, the panel of firms is linked to the Tax Registers (SSB_Banen) to obtain the actual number of employees per firm and by location. At the third step, this new dataset is merged with the Dutch Municipal Registers (GBA) to gather the actual number of foreign employees per firm, as well as their country of birth and various other demographic characteristics. As a result of our series of merges, we obtained a sample of 2789 firms that responded to both CIS surveys. Hence our dataset has a 2-wave panel with 5578 observations. These firms employ about one million workers of whom 11 percent are foreign born.

None of the datasets comprise information on the occupation and/or education of the employees. The large literature on earnings functions suggests a strong correlation between earnings and education (Card, 1999). Moreover, in the Netherlands the criterion to obtain a visa targeted at highly-skilled workers is to earn more than a given threshold level of earnings. From this perspective, we proceed to create three skill categories by assigning the employees into these categories based on their gross annual wages. The gross annual wage of each employee in the sampled firms is gathered from the SSB_Banen database. When assigning the employees to these categories, we benefitted from macro-level statistics provided on the Statistics Netherlands' website, which crosstabulates annual mean income of employees by education level. A similar tabulation of distribution of mean gross earnings of all employees against skill level (low, medium, high) is also available. Based on this information, we assigned people with a minimum gross annual wage of 42000 euro to the high skill category.

\section{Descriptive Statistics of the Sample}

As noted above, our sample is composed of a balanced panel of 2789 firms. Table 1 provides a range of summary statistics. On average, 41 percent declared being innovative over the 2000-2006 period. For about 86 percent of firms, innovation (as measured by the binary variable) was the same in the second wave as in the first wave. 365 firms innovated in the first period but not in the second, while 419 firms innovated in the second period but not in the first. Firms are clustered within various regions. The top five locations, where 34 percent of the firms are located, are: Great-Amsterdam, Great Rijnmond (Rotterdam), Utrecht, Twente and southeast North-Brabant.

\section{Table 1 about here}

There are 957667 employees in our sample, of whom 11 percent were born abroad. About 30 percent of the foreign workforce originates from the European continent. On average, there are 10 unique countries of birth represented in each firm and the co-location index is 0.264 . The mean 
Simpson index is 0.185 . Comparing the two waves, all measures of diversity increase (see Table 2). ${ }^{9}$ An increase in the size of the eastern-Europeans and east-Asians is noticeable (not shown in the table). Innovation activity increased also between 2002 and 2006. The foreigners are predominantly young and the share of high skilled foreign workers among the total foreign workforce is 19 percent on average (Table 1), but decreased from 21 percent in 2002 to 16 percent in 2006 (Table 2). This coincides with a period during which overall immigration in The Netherlands declined (e.g., Berkhout and Sudulich, 2011).

\section{Table 2 about here}

Our data predominantly comprise firms with 100 employees or more. The average firm size is 171 . Therefore, the results are suggestive mostly for large firms. There is no simple relationship between firm size and the number of foreigners the firm employs (See Figure 1). Instead, the foreign born are clustered in certain sectors. Large firms, however, are more likely to be diverse in terms of the unique number of countries of birth present, while they are not necessarily the most diverse in terms of overall composition.

\section{Figure 1 about here}

\section{Results of the Regression Analysis}

In this section, we proceed with reporting the regression analysis of the panel data. As described before, we are using a two-wave panel from 2000-2002 and 2004-2006 data and estimate linear probability models.

\subsection{All Firms}

The panel data regressions are estimated by means of fixed and random effects models with the data consisting of a balanced panel of 2789 firms observed twice. Table 3 shows 5 regressions. Specification 3.1 is a fixed effects model of innovation incidence with firm-level variables, regional controls and time fixed effects, but not employee characteristics. The results are in conformity with the innovation literature in that the firm's characteristics are important drivers of innovation. Firm size is, as expected, a significant factor (at the 1 percent level) that boosts innovation. A 10 percent increase in firm size increases the chances to innovate by 0.76 percent. Recently, the innovation literature emphasizes the importance of so-called soft factors, such as organizational restructuring, as the means through which a firm's prospect to innovate are increased. Regression 3.1 shows that firms that are open to change their organizational structure in relation to the third parties are 0.1 percentage points more likely to raise their innovation outputs than those which did not experience any organizational restructuring. Similarly, firms which reported costs and lack of personnel as obstacles to firm profitability and growth, appear to be more innovative. The reference values are no lack of personnel and no cost obstacles respectively. The results suggest that a lack of personnel is

\footnotetext{
${ }^{9}$ The Simpson index is uncorrelated with the natural logarithm of the unique number of birthplaces and with the co-location measure. The correlation coefficient between the natural logarithm of the unique number of birthplaces and the co-location is about -0.6 .
} 
an important driver of innovation (but differences between the low, medium and high levels of personnel shortage are not statistically significant). With respect to costs, the impact is nonlinear. A limited concern about costs raises innovation (relative to an absence of cost constraints), but with medium or high cost obstacles innovation is less (as it is also when there are no cost obstacles). We do not find a statistically significant impact of the competition and agglomeration variables in Specification (3.1) and subsequent specifications.

\section{Table 3 about here}

In specification 3.2 we add two measures for employee characteristics and three diversity measures. These are: the skill level and youthfulness of the foreign employees; the Simpson diversity index, colocation of foreign workers in total employment, and unique number of birthplaces in a firm, as defined in equations (2), (3) and (4), respectively. We do not find that within-firm changes in employee characteristics affect innovation. The likely reason is that the within-firm change in these variables over the four year period is rather small, compared with changes in firm characteristics such as due to restructuring and obstacles. Unfortunately, our empirical design does not constitute a natural experiment in which in a randomly selected number of firms, the number of foreigners is increased substantially. By and large, the change in innovation is triggered by a change in firm size, firm restructuring or by changes in personnel or cost obstacles. To better capture the impact of variables that change little over time, we use the random effects model (OLS gives qualitatively similar results but assumes an absence of unobserved firm heterogeneity). Therefore, all the following results are obtained through random effects estimation.

Specification 3.3 shows the results of the random effects model with the same specification as in 3.2. In addition to the variables mentioned already, 22 macro-sector dummies are included in these regressions to account for structural differences in innovation across sectors. We observe that the coefficients of firm variables are slightly larger while the significance levels are unchanged. One employee variable, however, now becomes statistically significant. Higher skilled foreign workers have a positive impact on innovation at the 5 percent level. A 1 percentage point increase in the intensity of high-skilled foreign employment in a firm leads to 0.06 percentage point increase in the probability to innovate.

The co-location index is also statistically significant. This is a measure of exposure to own kind, i.e. a measure of homogeneity of the foreign workforce. Our results suggest that the innovativeness of the firms is likely to decrease with increasing homogeneity of the foreign workforce at the firm level. The co-location index is negative and significant at the 1 percent level. The literature argues that clustering of workers from the similar origin may lead to grouping internally, exclusion of 'others' (non-group members), and create integration problems, since grouping with own-kind is mostly preferred over opening up to new cultures.

We find a negative effect of Simpson diversity index on probability to innovate. The coefficient is negative and significant at the 10 percent level. This index includes natives and is sensitive to the presence of the dominant groups. So, since the natives in the total employment of a firm are highly represented, the impact of this measure is likely to be influenced by the natives. We conclude that, on average, firms with a greater share of foreign-born are less innovative. This is consistent with earlier evidence, such as Ozgen et al. (2011). It is important to emphasize that the sample consist of all sectors in the economy including service sectors with predominantly low skilled foreign employees. Finally we do not find an impact of the unique variable and the youthfulness of the 
foreign employment in a firm for innovations as a whole. The time dummy coefficient (not reported in Table 3) is significant and negative; suggesting that the upward trend in innovation reported in Table 2 is due to changing firm and employee characteristics rather than a secular national increase in innovativeness. Sector dummies (also not reported due to space constraints) are as expected in terms of the literature. Firms in the Chemicals sector as well as in the Machinery and Equipment sectors are more likely to innovate than other sectors.

The data allow us to look into the impact of the various diversity measures on different innovation types. In specification 3.4 and 3.5, we report the results for product and process innovations, respectively. Since the coefficients of firm characteristics are robust over all the estimations, we will only discuss the impact of employee characteristics in the following regressions. We find that firms with a diverse composition of the foreign workforce generate more product and service innovations, but that such diversity has no impact on process innovations. The co-location variable is negative and significant at the 1 percent level for product innovations. In contrast, the unique number of birthplaces positively affects process innovations but not product innovations. A 1 percent increase in the number of birthplaces represented in a firm increases the probability to innovate by about 0.04 percentage points. Finally, the skill intensity of the foreign employees proves to be a crucial input that increases product innovations (significant at the 1 percent level). These results suggest that what matters for process innovation is the generation of new ideas and new perspectives that can come potentially from having a wider range of birthplaces represented among the firm's employees.

\subsection{Alternative Samples: Selected Group of Firms}

Foreigners tend to cluster more in some sectors than others, and innovation activity also varies considerably across sectors. Even if immigrants are concentrated in sectors that are not innovative (such as cleaning services) and an inverse relationship is therefore found at the macro level between the employment of foreigners and innovation, there may still be benefits of a diverse workforce for firms in sectors that are highly innovative. To explore sector-driven heterogeneity, we take some sub-samples from our firm data. These sub-samples are obtained by considering the migration and innovation literatures. We are also guided by what our panel data suggest in the case of Netherlands, since every country has to some extent different economic and social dynamics. This section reports the regression results based on these selected sub-samples.

The first set of regressions refers to the orientation of the markets in which the firms sell their products and services. There is a large literature focusing on firms' trade links, and how they benefit from immigrant/foreign workers (Genc et al., 2012). Table 4 reports the impact of workforce diversity on various innovation types, once the market orientation of the firms is considered. The CIS surveys ask the firms explicitly to indicate for which market(s) they target to sell their goods. The first 3 regressions, (4.1)-(4.3), are based on a sub-sample of 1431 firms that focus on international markets (countries of the European Union and European Free Trade Association; EU candidate countries; and all other countries) while specifications (4.4)-(4.6) refer to firms that report a domestic orientation. These firms report that they sell good/services and/or processes for domestic markets (local/regional and national markets of the Netherlands). For clarity, the table shows only results with respect to diversity and the characteristics of immigrant employees. 
Qualitatively, the results are quite similar between an international orientation and a domestic orientation (note that the two are not mutually exclusive: the total number of firms is 2739 , of who 1431 report an international orientation and 2671 a domestic orientation). The table shows that the impact of the co-location index is negative and very significant, except for process innovations, among firms that have an international or domestic markets orientation. On the other hand, the richness of the labour force, in the form of the unique number of birthplaces represented in a firm, is a significant driver of process innovations at the 1 percent level, while it has no impact on product innovations (but is significant for innovations overall among internationally oriented firms).

\section{Table 4 about here}

The big difference between an international orientation and a domestic orientation is the coefficient of co-location (which is larger in absolute value for product innovations among internationally oriented firms) and the impact of high-skill intensity of foreign employment, which affects firms with an international orientation more than firms with a domestic orientation. Homogeneity of foreign employees (as measured by the co-location variable) particularly hinders product innovation of internationally oriented firms, as the trade facilitation literature suggests. Firms in both categories benefit from highly-skilled employees, particularly, in terms of product innovations.

Our second sub-sample excludes the sectors in which low-skilled foreign labour is mostly concentrated. Low-skilled foreign labour may cluster in sectors such as construction, cleaning and retail trade that are not necessarily striving to reach an innovative edge. The top four sectors where the fraction of low-skilled foreign workers per firm is the highest are: Low-skilled Business Services (Cleaning, security, call centres, secretaries, photography developers etc); Retail Trade; Hotels and Restaurants; and Manufacturing not elsewhere classified (Furniture, Recycling, etc.). These sectors are excluded from the sub-sample. Once these sectors with low-skilled foreigners are excluded, we observe that the coefficients of the diversity measures become slightly more significant and larger (Table 5). The exposure to own-kind measure - co-location index- is significant and negative, except for process innovations, at the 1 percent level, while the coefficient of the natural logarithm of the number of countries of birth represented in the firm is positive and significant for process innovations and for innovations as a whole. High skill intensity of foreign employment continues to benefit product innovation.

\section{Table 5 about here}

\subsection{Robustness Checks}

With the regressions presented so far the question remains whether the innovativeness of the firms is increasing due to the diversity of the employee composition or whether immigrant workers are sorted into firms that are more innovative. We address this potential endogeneity problem in two different ways. First, we re-estimate specifications (3.3)-(3.5) by fixing the diversity measures at their value in year 2000. We therefore control for possible endogenous sorting over the 2002-2006 period during which innovation is measured. The results are reported in Table 6. Secondly, we utilize an instrumental variables (IV) estimation in which we instrument the Simpson index with two exogenous variables. Those results are reported in Table 7. 
Our panel data set is composed of two waves with four years in between. It is possible that the innovation output of the first period influences the sorting of foreign labour across firms in the second period, thereby biasing the estimated impact of diversity on innovation. Hence, we repeat the econometric specifications (3.3)-(3.5) in Table 3, but fix all of the measures on the composition and richness of diversity at their values in 2000 (see Table 6). This provides in column (6.1) additional evidence that extensive homogeneity (co-location) is bad for innovation, while In(unique) has positive and statistically significant coefficients. A high value of the Simpson index implies a low share of native born, and this also lowers innovation in regressions (6.1) and (6.2) as in previous regressions. High-skill intensity and youthfulness have also positive impacts on the innovation propensity, specifically product innovations. Hence these regressions confirm that the youthfulness of foreign employees (the share of those aged 25-44) has a positive impact on innovation.

\section{Instrumental Variables Estimations}

The strongest assumption we made so far is that our estimations do not suffer from a reverse causality in the relationship between migration and innovation. Finding a country-wide natural experiment at the firm level to avoid this reverse causality is simply not realistic. It is, however, possible to account for potential bias by instrumental variables estimation which is by far the most common technique to address the endogeneity issues in non-experimental studies. We instrument the Simpson index with two exogenous variables that do not correlate with the error term of the regression but that are good predictors of the composition of the overall workforce in firms.

Firstly we introduce a novel instrument, namely the total number of foreign restaurants per municipality. We argue that the presence of foreign restaurants in an area can be an obvious cause of sorting the foreign workers (Clark, 2002; Shapiro, 2003; Florida, 2003). While there is some commuting between municipalities, the supply of foreign workers is largely local. On the other hand, it is implausible (and often impossible given zoning regulations) that innovative firms spatially sort in terms of the availability of foreign restaurants. Of course, over the period considered innovative firms could recruit foreign workers who trigger a demand for foreign restaurants. However, the restaurant density is calculated at a time that preceded the panel data. Hence, for the first and second wave of the panel data, we use restaurant density data from 1996 and 1998, respectively. Admittedly, deeper lagging would be preferable but this is not feasible with the available data. The source of the data on ethnic restaurant location is the HORECA dataset in the Netherlands. ${ }^{10}$

\section{Table 7 about here}

\footnotetext{
${ }^{10}$ HORECA is an acronym for Hotels, Restaurants and Cafes. This dataset covers the registered bars, restaurants, hotels and all the other businesses in this sector. The data coverage is good. The data are currently available from 1996 until 2007. The number of foreign restaurants is counted at the municipal level by the nationality of the cuisine at the time of registration. For each restaurant, the main location is registered; no franchise branches are registered. This leads to unique listing, and excludes double counting. Moreover, restaurants with a combined Dutch/French cuisine are excluded from the total.
} 
Secondly, we also use the natural logarithm of the lagged "allochtoon" population per municipality (again the same way we lagged the restaurant density data). The historical presence of immigrant population act as a magnet to attract more immigrants in certain areas and foreigners motivation to immigrate may vary substantially over time. The instruments explain 7 percent of the betweenvariation in the simpson index, and the lagged total number of foreign restaurants per municipality appears as a strong instrument with the F-test statistic is larger than 10. The results and IV test statistics are given in Table 7. We find that our previous results are robust to IV estimation but the instrumented Simpson index is no longer statistically significant.

It is again confirmed that the co-location measure is negative and significant for innovation as a whole and product innovation at the 1 percent level, while these are boosted by increasing highskilled intensity of foreign employment. Process innovations benefit significantly from any unique cultural background. The magnitudes of the coefficients are fairly similar to those in the previous estimations in Table 3.

\section{Conclusion}

In this paper we used micro data from The Netherlands to investigate links between innovation activity at the firm level and the presence of immigrants among the firm's employees. We constructed a unique dataset that linked two innovation surveys with administrative and tax data on firms and on workers. This dataset permitted us to identify the human capital of immigrant workers (in terms of age and broad skills) and their diversity by country of origin. The latter was defined in three different ways: the overall diversity in firm employment measured by the Simpson index, a colocation index (that measures cultural homogeneity among the foreign-born), and the unique number of birthplaces present.

We estimated a wide range of linear probability models and found particularly robust evidence that cultural homogeneity as measured by the co-location index has a negative effect on innovation. This can be seen from Table 8 which summarises the results of this paper. The table shows that at the firm level, different components of diversity benefit different types of innovation at varying magnitudes. Not all forms of diversity are good as a whole, while not all types of innovations are equally influenced by diversity. A greater Simpson index, roughly corresponding with a smaller share of Netherlands-born employees, sometimes lowers innovation. However, greater diversity among immigrant employees (measured by a smaller co-location index) has a positive impact on product innovation, while the cultural 'richness' of the work force (measured by the unique number of birthplaces present) boosts process innovation. The results also show that the skill intensity of foreign employment enhances innovation. Skills clearly matter for innovation. The results are robust to accounting for a possible endogeneity bias.

\section{Table 8 about here}

The positive effect of diversity should not, however, be overstated. As the literature shows, innovation is predominantly driven by firm scale, performance, external conditions and institutions. In any case, different types of innovations have different requirements. Moreover, the evidence 
reported here is not informative of exactly how the employment of immigrants affects innovation. Early in this paper we reviewed a wide range of channels through which immigrant workers can positively or negatively impact on a firm's ability to innovate. In order to investigate which of these channels operate in practice and contribute most to the observed outcomes, a new research approach might be desirable. These could include experimental designs and the analysis of surveys at the firm level. Mixed qualitative and quantitative methods may also be helpful. The contribution of second generation migrants, who are often better educated than new arrivals, to innovation is also a promising avenue for further research. However, such additional research is unlikely to overturn the key message of the present paper that policies that promote the recruitment of highskilled talent from abroad may not only assist in alleviating shortages in certain types of specialised employment, but may also contribute to a nation's innovation capacity when such talent is recruited from a wide range of source countries.

\section{References}

Acs, A.J. and Audretsch, D.B. (1988) Innovation in large and small firms: an empirical analysis. American Economic Review 78(4): 678-690.

Alesina, A. and La Ferrara, E. (2005) Ethnic diversity and economic performance. Journal of Economic Literature 43(3): 762-800.

Alvarez, J., Forrest, D., Sanz, I. and Tena, J.D. (2011) Impact of importing foreign talent on performance levels of local co-workers. Labour Economics 18: 287-296.

Angrist, J.D. (2001) Estimation of limited dependent variable models with dummy endogenous regressors: Simple strategies for empirical practice. Journal of Business and Economic Statistics 19 (1): 2-16.

Audretsch, D.B. and Feldman, M.P. (2004) Knowledge spillovers and the geography of innovation, Handbook of Regional and Urban Economics 4: 2713-2739.

Beaverstock, J.V., Hall, S. (2012). Competing for talent: global mobility, immigration and the City of London's labour market. Cambridge Journal of Regions, Economy and Society, 5: (271-287).

Bell, S.T., Villado, A.J., Lukasik, M.A., Belau, L. and Briggs, A.L. (2011) Getting Specific about Demographic Diversity Variable and Team Performance Relationships: A Meta-Analysis. Journal of Management, 37(3): 709-743.

Berkhout, J. and Sudulich,L. (2011) Demographics of Immigration: The Netherlands. SOM Working Paper No. 2011-07, University of Amsterdam.

Borjas, G.J. (2001) Does immigration grease the wheels of the labor market? Brookings Papers on Economic Activity 2001(1): 69-119.

Card, D. (1999) The causal effect of education on earnings. In: O.C. Ashenfelter and D. Card (eds) Handbook of Labor Economics, Volume 3, Part A, 1801-1863.

Clark, T.N., Lloyd, R., Wong, K.K., Jain, P. (2002) Amenities drive urban growth. Journal of Urban Affairs, 24: 493-515.

Cutler, D. M., Glaeser, E. L. and Vigdor, J. L. (2008) Is the melting pot still hot? Explaining the resurgence of immigrant segregation. Review of Economics \& Statistics 90(3): 478-497.

de Graaff, T. and Nijkamp, P. (2010) Socio-Economic Impacts of Migrant Clustering on Dutch Neighbourhoods: In Search of Optimal Migrant Diversity. Socio-Economic Planning Sciences 44: 231-239

Dosi, G. (1988) Sources, procedures, and microeconomic effects of innovation. Journal of Economic Literature 26(3): 1120-1171.

Ely, R.J. and Thomas, D.A. (2001) Cultural diversity at work: the effects of diversity perspectives on work group processes and outcomes. Administrative Science Quarterly 46(2): 229-273.

Florida, R. (2003) Cities and the Creative Class. City \& Community 2:1 March. 
Forbes (2011) Growing diversity and inclusion: fostering innovation through a diverse workforce. Forbes Insights. New York: Forbes.

Genc, M., Gheasi, M., Nijkamp, P. and Poot, J. (2012) The impact of immigration on international trade: a meta-analysis. In: Nijkamp P, Poot J and M Sahin (eds) Migration Impact Assessment: New Horizons. Cheltenham UK: Edward Elgar, pp. 301-337.

Hunt, J., Gauthier-Loiselle, M. (2010) How much does immigration boost innovation? American Economic Journal: Macroeconomics 2: 31-56.

Jacobs, J. (1969) The Economy of Cities. London: Vintage.

Jaeger, D.A. and Duleep, H.O. (2010) The Effect of Immigration on U.S. Natives' Innovation and Entrepreneurship. Paper presented at the 2010 conference of the European Association of Labour Economists.

Jensen, M.B., Johnson, B., Lorenz, E., Lundvall, B.A. (2007) Forms of knowledge and modes of innovation. Research Policy. 36: 680-693.

Jones, C.I., Romer, P.M. (2010) The New Kaldor Facts: Ideas, Institutions, Population, and Human Capital. American Economic Journal: Macroeconomics. 2(1): 224-245.

Kerr, W.R. (2010) Breakthrough inventions and migrating clusters of innovation. Journal of Urban Economics 67: 46-60.

Kerr, W.R. and Lincoln, W. (2010) The supply side of innovation: H1-B visa reform and US ethnic invention. NBER WP 15768. Cambridge Mass.: NBER.

Lee, N. and Nathan, M. (2010) Knowledge workers, cultural diversity and innovation: evidence from London. International Journal on Knowledge-Based Development. 1 (1-2): 53-78.

Lobo, J. and Strumsky, D. (2008) Metropolitan patenting, inventor agglomeration and social networks: A tale of two effects. Journal of Urban Economics 63: 871-884.

Maré, D.C., Fabling, R. and Stillman, S. (2011) Immigration and innovation. IZA DP 5686. Bonn: IZA Institute for the Study of Labor.

Niebuhr, A. (2010) Migration and innovation: Does cultural diversity matter for regional R\&D activity? Papers in Regional Science 89: 563-585.

Niebuhr, A. and Peters, C. (2012) Labour diversity and firm's innovation: Evidence from Germany. Nuremburg: IAB Institute for Employment Research.

Nijkamp, P. and Poot, J. (2012) Cultural diversity: a matter of measurement. Department of Spatial Economics. VU University Amsterdam.

$\varnothing$ stergaard, C.R., Timmermans, B. and Kristinsson, K. (2011) Does a different view create something new? The effect of employee diversity on innovation. Research Policy 40: 500-509.

Ottaviano, G. and Peri, G. (2006) The economic value of cultural diversity: evidence from US cities. Journal of Economic Geography 6: 9-44.

Ozgen, C., Nijkamp, P., Poot, J. (2012). Immigration and Innovation in European Regions. In Migration Impact Assessment: New Horizons, Nijkamp, N., Poot, J., and Sahin, M. (eds). Edward Elgar Publishing.

Ozgen C., Nijkamp, P., Poot, J. (2011) The impact of cultural diversity on innovation: evidence from Dutch firm level data. IZA DP 6000. Bonn: IZA Institute for the Study of Labor.

Page, S. (2007) The Difference: How the Power of Diversity Creates Better Groups, Firms, Schools, and Societies. Princeton University Press.

Parotta, P., Pozzoli, D. and Pytlikova, M. (2011) The nexus between labour diversity and firm's Innovation. Norface Migration Discussion Paper No. 2011-5, www.norface-migration.org.

Poot, J. (2008) Demographic change and regional competitiveness: The effects of immigration and ageing. International Journal of Foresight and Innovation Policy 4(1/2): 129-145.

Poot, J., Waldorf, B. and van Wissen, L. (eds) (2008) Migration and Human Capital. Edward Elgar, Cheltenham UK.

Romer, P.M. (1990) Endogenous Technological Change. Journal of Political Economy, 98 (2): S71-S102.

Shapiro, J.M. (2003) Smart Cities: Explaining the Relationship between City Growth and Human Capital. NBER Working paper (June 19), Cambridge Mass.: NBER. 
Südekum, J., Wolf, K. and Blien, U. (2009) Cultural diversity and local labour markets, IZA DP 4619. Bonn: IZA Institute for the Study of Labor.

Uzzi, B. and Dunlap, S. (2005). How to build your network. Harvard Business Review, 83: 2-11.

Zucker, L.G. and Darby, M.R. (2007) Star Scientists, innovation and regional and national immigration. NBER WP 13547. Cambridge Mass.: NBER

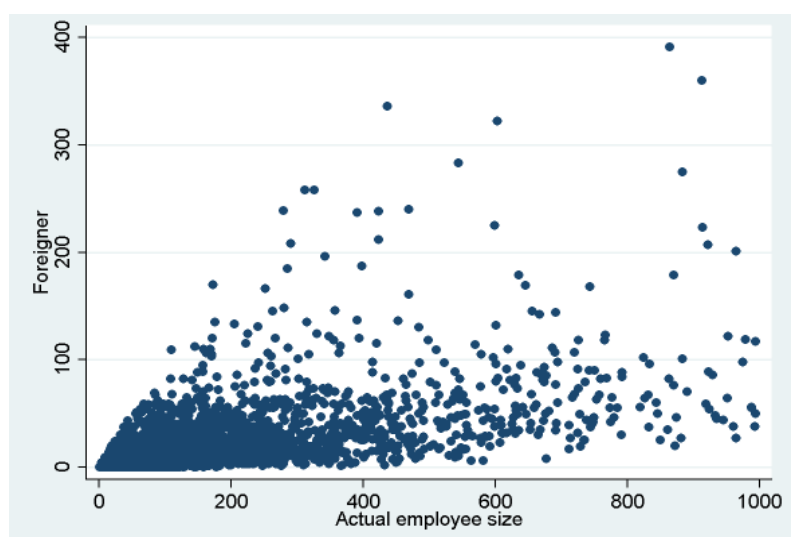

Figure 1: Scatter Plot of the Number of Foreign Employees and Firm Size

Table 1: Summary Statistics ${ }^{a}$

\begin{tabular}{|c|c|c|c|}
\hline Variable & $\mathbf{N}$ & Mean & Std. Dev \\
\hline Firm innovated & 5578 & 0.4087 & 0.4916 \\
\hline Firm innovated products & 5578 & 0.2927 & 0.4550 \\
\hline Firm innovated processes & 5578 & 0.2496 & 0.4328 \\
\hline Firm size & 5578 & 171 & 355 \\
\hline Firm's openness to change & 5578 & 0.1409 & 0.3479 \\
\hline Obstacles: Lack of personnel & 5578 & 0.3844 & 0.7777 \\
\hline Obstacles: Cost & 5578 & 0.3308 & 0.7582 \\
\hline Number of firms per job (Nuts 3 level) & 5578 & 0.1047 & 0.0212 \\
\hline Number of firms per municipality & 5578 & 56.95 & 53.08 \\
\hline Co-location index & 5578 & 0.264 & 0.395 \\
\hline Unique number of birthplaces & 5578 & 10 & 12 \\
\hline Simpson index & 5578 & 0.1857 & 0.1760 \\
\hline High-skill intensity of foreign employment ${ }^{b}$ & 5578 & 0.1877 & 0.2422 \\
\hline Youthfulness of foreign employment ${ }^{\mathrm{c}}$ & 5578 & 0.5732 & 0.3249 \\
\hline “Allochtoon" population per municipality ${ }^{d}$ & 5578 & 37766 & 78283 \\
\hline Number of foreign restaurants per municipality & 5578 & 63 & 144 \\
\hline
\end{tabular}

Notes: ${ }^{a}$ Due to the confidentiality agreement with Statistics Netherlands, minimum and maximum values of the variables cannot be displayed in Table $1 .{ }^{\mathrm{b}}$ Share of highly-skilled foreigners in total foreign employment per firm. ${ }^{\mathrm{c}}$ Share of foreigners aged 25-44 in total foreign employment per firm. ${ }^{d}$ In the Netherlands this terms refers to persons who have at least one parent who was born abroad. 
Table 2: Mean Values of the Key Variables in 2002 and 2006

\begin{tabular}{lrr}
\hline Variables & $\mathbf{2 0 0 2}$ & $\mathbf{2 0 0 6}$ \\
\hline \multicolumn{1}{c}{ Firm Variables } & Mean & Mean \\
\hline Firm innovated & 0.39 & 0.42 \\
Firm innovated products & 0.28 & 0.29 \\
Firm innovated processes & 0.21 & 0.28 \\
\hline \multicolumn{1}{c}{ Employee Variables } & Mean & Mean \\
\hline Co-location & 0.275 & 0.252 \\
Unique number of birthplaces & 9.9 & 10.6 \\
Simpson index & 0.181 & 0.190 \\
High-skill intensity of foreign employment & 0.21 & 0.16 \\
Youthfulness of foreign employment & 0.58 & 0.56 \\
\hline Number of foreign employees & 50442 & 55145 \\
Number of employees & 466654 & 491013 \\
\hline
\end{tabular}


Table 3: Linear Probability Regression Models of Firm Innovation

\begin{tabular}{|c|c|c|c|c|c|}
\hline VARIABLES & $\begin{array}{c}(3.1) \\
\text { innovative }\end{array}$ & $\begin{array}{c}(3.2) \\
\text { innovative }\end{array}$ & $\begin{array}{c}(3.3) \\
\text { innovative }\end{array}$ & $\begin{array}{c}(3.4) \\
\text { product }\end{array}$ & $\begin{array}{c}(3.5) \\
\text { Process }\end{array}$ \\
\hline Log firm size & $\begin{array}{c}0.076 * * * \\
(0.0218)\end{array}$ & $\begin{array}{c}0.069 * * * \\
(0.0251)\end{array}$ & $\begin{array}{c}0.066^{* * * *} \\
(0.009)\end{array}$ & $\begin{array}{c}0.0510 * * * \\
(0.008)\end{array}$ & $\begin{array}{c}0.0465 * * * \\
(0.008)\end{array}$ \\
\hline Obstacles: Lack of personnel (low level) ${ }^{\mathrm{a}}$ & $\begin{array}{c}0.142 * * * \\
(0.0248)\end{array}$ & $\begin{array}{c}0.142 * * * \\
(0.0248)\end{array}$ & $\begin{array}{c}0.194 * * * \\
(0.0201)\end{array}$ & $\begin{array}{c}0.171 * * * \\
(0.0204)\end{array}$ & $\begin{array}{c}0.104 * * * \\
(0.0224)\end{array}$ \\
\hline Obstacles: Lack of personnel (medium level) ${ }^{\mathrm{a}}$ & $\begin{array}{c}0.109 * * * \\
(0.0288)\end{array}$ & $\begin{array}{c}0.109 * * * \\
(0.0289)\end{array}$ & $\begin{array}{c}0.169 * * * \\
(0.0236)\end{array}$ & $\begin{array}{c}0.179 * * * \\
(0.0232)\end{array}$ & $\begin{array}{c}0.120 * * * \\
(0.0251)\end{array}$ \\
\hline Obstacles: Lack of personnel (high level) ${ }^{\mathrm{a}}$ & $\begin{array}{c}0.145^{* * *} \\
(0.0404)\end{array}$ & $\begin{array}{l}0.145^{* * * *} \\
(0.0405)\end{array}$ & $\begin{array}{c}0.198 * * * \\
(0.0328)\end{array}$ & $\begin{array}{c}0.175 * * * \\
(0.0356)\end{array}$ & $\begin{array}{c}0.150 * * * \\
(0.0374)\end{array}$ \\
\hline Obstacles: Cost (low level) ${ }^{\mathrm{a}}$ & $\begin{array}{l}0.058 * * \\
(0.0278)\end{array}$ & $\begin{array}{c}0.0584 * * \\
(0.0279)\end{array}$ & $\begin{array}{c}0.109 * * * \\
(0.0226)\end{array}$ & $\begin{array}{c}0.0601 * * * \\
(0.0231)\end{array}$ & $\begin{array}{c}0.118 * * * \\
(0.0258)\end{array}$ \\
\hline Obstacles: Cost (medium level) ${ }^{\mathrm{a}}$ & $\begin{array}{l}-0.0253 \\
(0.0306)\end{array}$ & $\begin{array}{l}-0.0245 \\
(0.0307)\end{array}$ & $\begin{array}{c}0.0276 \\
(0.0252)\end{array}$ & $\begin{array}{l}0.0467 * \\
(0.0250)\end{array}$ & $\begin{array}{c}0.0432 \\
(0.0274)\end{array}$ \\
\hline Obstacles: Cost (high level) ${ }^{\mathrm{a}}$ & $\begin{array}{l}-0.0567 \\
(0.0419)\end{array}$ & $\begin{array}{l}-0.0559 \\
(0.0419)\end{array}$ & $\begin{array}{c}-0.006 \\
(0.0340)\end{array}$ & $\begin{array}{l}-0.0110 \\
(0.0335)\end{array}$ & $\begin{array}{r}-0.0278 \\
(0.033)\end{array}$ \\
\hline Openness to change & $\begin{array}{c}0.097 * * * \\
(0.0229)\end{array}$ & $\begin{array}{c}0.097 * * * \\
(0.0229)\end{array}$ & $\begin{array}{c}0.173 * * * \\
(0.0172)\end{array}$ & $\begin{array}{c}0.181 * * * \\
(0.0172)\end{array}$ & $\begin{array}{c}0.178 * * * \\
(0.0181)\end{array}$ \\
\hline Number of firms per job (Nuts3 level) & $\begin{array}{c}0.760 \\
(2.408)\end{array}$ & $\begin{array}{c}0.775 \\
(2.407)\end{array}$ & $\begin{array}{r}-0.0371 \\
(0.371)\end{array}$ & $\begin{array}{l}-0.194 \\
(0.349)\end{array}$ & $\begin{array}{c}0.313 \\
(0.338)\end{array}$ \\
\hline $\operatorname{Ln}$ (number of firms per municipality) & $\begin{array}{l}0.143 \\
(0.195)\end{array}$ & $\begin{array}{c}0.144 \\
(0.195)\end{array}$ & $\begin{array}{c}-0.0112 \\
(0.01)\end{array}$ & $\begin{array}{r}-0.010 \\
(0.01)\end{array}$ & $\begin{array}{l}-0.0098 \\
(0.007)\end{array}$ \\
\hline Co-location & - & $\begin{array}{r}-0.0204 \\
(0.033)\end{array}$ & $\begin{array}{c}-0.0583^{* * *} \\
(0.0197)\end{array}$ & $\begin{array}{c}-0.0504 * * * \\
(0.0179)\end{array}$ & $\begin{array}{c}-0.001 \\
(0.0173)\end{array}$ \\
\hline $\operatorname{Ln}$ (unique) & - & $\begin{array}{c}0.006 \\
(0.0292)\end{array}$ & $\begin{array}{c}0.0217 \\
(0.0138)\end{array}$ & $\begin{array}{c}0.0110 \\
(0.0124)\end{array}$ & $\begin{array}{c}0.0357 * * * \\
(0.0128)\end{array}$ \\
\hline Simpson index & - & $\begin{array}{r}-0.0324 \\
(0.127)\end{array}$ & $\begin{array}{c}-0.0983 * \\
(0.0538)\end{array}$ & $\begin{array}{l}-0.0675 \\
(0.0481)\end{array}$ & $\begin{array}{l}-0.0549 \\
(0.0492)\end{array}$ \\
\hline High-skill intensity of foreign employment & - & $\begin{array}{c}0.0192 \\
(0.0436)\end{array}$ & $\begin{array}{c}0.0610 * * \\
(0.0274)\end{array}$ & $\begin{array}{c}0.0851 * * * \\
(0.0251)\end{array}$ & $\begin{array}{c}0.01 \\
(0.0244)\end{array}$ \\
\hline Youthfulness of foreign employment & - & $\begin{array}{c}0.007 \\
(0.0306)\end{array}$ & $\begin{array}{c}0.0308 \\
(0.0196)\end{array}$ & $\begin{array}{c}0.0120 \\
(0.0177)\end{array}$ & $\begin{array}{c}-0.001 \\
(0.0178)\end{array}$ \\
\hline Constant & $\begin{array}{l}-0.573 \\
(0.654)\end{array}$ & $\begin{array}{l}-0.517 \\
(0.655)\end{array}$ & $\begin{array}{c}0.182 * * \\
(0.080)\end{array}$ & $\begin{array}{c}0.118 \\
(0.0742)\end{array}$ & $\begin{array}{c}-0.08 \\
(0.0732)\end{array}$ \\
\hline $\mathrm{N}$ & 5578 & 5578 & 5578 & 5578 & 5578 \\
\hline$\overline{\mathrm{R}^{2} \text { between }}$ & 0.047 & 0.049 & 0.377 & 0.350 & 0.255 \\
\hline $\mathrm{R}_{\text {_within }}$ & 0.034 & 0.034 & 0.027 & 0.029 & 0.034 \\
\hline $\mathrm{R}^{2}$ _overall & 0.041 & 0.043 & 0.270 & 0.253 & 0.168 \\
\hline Estimation Technique & $\mathrm{FE}$ & FE & RE & RE & RE \\
\hline
\end{tabular}

Notes: ${ }^{a}$ The reference category for the obstacle variables referring to a lack of personnel and to cost is in both cases: no obstacle reported. All estimations include sector and time fixed effects. ${ }^{* * *} p<0.01,{ }^{* *} p<0.05, * p<0.1$. Robust standard errors are given in parentheses. 
Table 4: Results for Sub-samples of Firms with International and Domestic Orientation ${ }^{1}$

\begin{tabular}{|c|c|c|c|c|c|c|}
\hline VARIABLES & $\begin{array}{l}\text { (4.1) } \\
\text { International } \\
\text { Orientation } \\
\text { innovative }\end{array}$ & $\begin{array}{c}(4.2) \\
\text { International } \\
\text { Orientation } \\
\text { product }\end{array}$ & $\begin{array}{c}\text { (4.3) } \\
\text { International } \\
\text { Orientation } \\
\text { process }\end{array}$ & $\begin{array}{c}(4.4) \\
\text { Domestic } \\
\text { Orientation } \\
\\
\text { innovative }\end{array}$ & $\begin{array}{c}(4.5) \\
\text { Domestic } \\
\text { Orientation } \\
\\
\text { product }\end{array}$ & $\begin{array}{c}(4.6) \\
\text { Domestic } \\
\text { Orientation } \\
\text { process }\end{array}$ \\
\hline Co-location & $\begin{array}{c}-0.0579 * \\
(0.0306)\end{array}$ & $\begin{array}{c}-0.066^{* *} \\
(0.0302)\end{array}$ & $\begin{array}{l}-0.0292 \\
(0.0275)\end{array}$ & $\begin{array}{c}-0.0641 * * * \\
(0.0202)\end{array}$ & $\begin{array}{c}-0.0541 * * * \\
(0.0184)\end{array}$ & $\begin{array}{c}-0.001 \\
(0.0177)\end{array}$ \\
\hline Ln(unique) & $\begin{array}{c}0.0491 * * \\
(0.0242)\end{array}$ & $\begin{array}{c}0.0296 \\
(0.0234)\end{array}$ & $\begin{array}{c}0.0638 * * * \\
(0.0236)\end{array}$ & $\begin{array}{c}0.0185 \\
(0.0144)\end{array}$ & $\begin{array}{c}0.008 \\
(0.0128)\end{array}$ & $\begin{array}{c}0.0344 * * * \\
(0.0132)\end{array}$ \\
\hline Simpson index & $\begin{array}{c}-0.174 * * \\
(0.0876)\end{array}$ & $\begin{array}{c}-0.066 \\
(0.0854)\end{array}$ & $\begin{array}{c}-0.113 \\
(0.0853)\end{array}$ & $\begin{array}{c}-0.0971 * \\
(0.0551)\end{array}$ & $\begin{array}{r}-0.0584 \\
(0.050)\end{array}$ & $\begin{array}{l}-0.0556 \\
(0.0509)\end{array}$ \\
\hline High-skill intensity of foreign employment & $\begin{array}{c}0.0418 \\
(0.0370)\end{array}$ & $\begin{array}{c}0.102 * * * \\
(0.0359)\end{array}$ & $\begin{array}{c}0.001 \\
(0.0359)\end{array}$ & $\begin{array}{c}0.0649 * * \\
(0.0282)\end{array}$ & $\begin{array}{c}0.0794 * * * \\
(0.0258)\end{array}$ & $\begin{array}{c}0.005 \\
(0.0252)\end{array}$ \\
\hline Youthfulness of foreign employment & $\begin{array}{c}0.0408 \\
(0.0296)\end{array}$ & $\begin{array}{l}-0.0164 \\
(0.0292)\end{array}$ & $\begin{array}{c}0.0171 \\
(0.0287)\end{array}$ & $\begin{array}{c}0.0241 \\
(0.0200)\end{array}$ & $\begin{array}{c}0.007 \\
(0.0180)\end{array}$ & $\begin{array}{c}-0.002 \\
(0.0182)\end{array}$ \\
\hline $\mathrm{N}$ & 2862 & 2862 & 2862 & 5342 & 5342 & 5342 \\
\hline $\begin{array}{l}\overline{\mathrm{R}^{2} \_ \text {between }} \\
\mathrm{R}^{2} \text { _within } \\
\mathrm{R}^{2} \text { overall }\end{array}$ & $\begin{array}{l}0.388 \\
0.024 \\
0.279\end{array}$ & $\begin{array}{l}0.352 \\
0.031 \\
0.261\end{array}$ & $\begin{array}{l}0.254 \\
0.035 \\
0.169\end{array}$ & $\begin{array}{c}0.380 \\
0.026 \\
0.272\end{array}$ & $\begin{array}{c}0.349 \\
0.028 \\
0.254\end{array}$ & $\begin{array}{c}0.261 \\
0.036 \\
0.173\end{array}$ \\
\hline
\end{tabular}


Table 5: Results for a Sub-sample of Firms in which Sectors with the Highest Share of Low-skilled Foreigners are Excluded

\begin{tabular}{lccc}
\hline VARIABLES & $(5.1)$ & $(5.2)$ & $(5.3)$ \\
process
\end{tabular}

Notes: Excluded sectors are Low-skilled Business Services (Cleaning, security, call centres, secretaries, photography developers etc), Retail Trade, Hotels and Restaurants, and Manufacturing not elsewhere classified (Furniture, Recycling, etc). All estimations include the same variables on firm and regional characteristics as in Table 1 , as well as sector and time fixed effects. Specifications are estimated with the random effects model. ${ }^{* * *} p<0.01,{ }^{* *} p<0.05,{ }^{*} p<0.1$. Robust standard errors are given in parentheses.

Table 6: Results with Predetermined and Time-Invariant Diversity Measures

\begin{tabular}{|c|c|c|c|}
\hline VARIABLES & $\begin{array}{c}(6.1) \\
\text { innovative }\end{array}$ & $\begin{array}{c}(6.2) \\
\text { product }\end{array}$ & $\begin{array}{c}(6.3) \\
\text { process }\end{array}$ \\
\hline \multirow[t]{2}{*}{ Co-location $^{1}$} & $-0.0529 * * *$ & $-0.0422 * *$ & -0.0001 \\
\hline & $(0.0204)$ & $(0.0185)$ & $(0.0181)$ \\
\hline \multirow[t]{2}{*}{$\operatorname{Ln}(\text { unique })^{1}$} & $0.0290^{* *}$ & $0.0242 *$ & $0.0366^{* * *}$ \\
\hline & $(0.0142)$ & $(0.0131)$ & $(0.0128)$ \\
\hline \multirow[t]{2}{*}{ Simpson index ${ }^{1}$} & $-0.130 * *$ & $-0.0964 *$ & -0.0659 \\
\hline & $(0.0552)$ & $(0.050)$ & $(0.0492)$ \\
\hline \multirow[t]{2}{*}{ High-skill intensity of foreign employment } & $0.0628 * *$ & $0.0862 * * *$ & -0.004 \\
\hline & $(0.0273)$ & $(0.0250)$ & $(0.0243)$ \\
\hline \multirow[t]{2}{*}{ Youthfulness of foreign employment } & $0.0361 *$ & $0.0141 *$ & 0.003 \\
\hline & $(0.0191)$ & $(0.0172)$ & $(0.0175)$ \\
\hline $\mathrm{N}$ & 5586 & 5586 & 5586 \\
\hline$\overline{\mathrm{R}^{2} \text { _between }}$ & 0.380 & 0.347 & 0.253 \\
\hline $\mathrm{R}^{2}$ _within & 0.026 & 0.028 & 0.0340 \\
\hline $\mathrm{R}^{2}$ _overall & 0.270 & 0.251 & 0.167 \\
\hline
\end{tabular}

Notes: ${ }^{1}$ The variables listed above have been fixed at their 2000 values. All estimations include the same variables on firm and regional characteristics as in Table 1, as well as sector and time fixed effects. Specifications are estimated with the random effects model. ${ }^{* * *} \mathrm{p}<0.01,{ }^{* *} \mathrm{p}<0.05,{ }^{*} \mathrm{p}<0.1$. Robust standard errors are given in parentheses. 
Table 7: Instrumental Variables Estimations

\begin{tabular}{lc}
\hline $1^{\text {st }}$ Stage Estimation & Simpson index \\
\hline Total number of foreign restaurants per municipality & $0.001 * * *$ \\
& $(0.0001)$ \\
Share of allochtoon population per municipality & $0.024 * * *$ \\
& $(0.002)$ \\
\hline $\mathrm{N}$ & 5578 \\
\hline $\mathrm{R}^{2} \_$between & 0.073 \\
$\mathrm{R}^{2} \_$within & 0.001 \\
$\mathrm{R}^{2} \_$overall & 0.069 \\
\hline
\end{tabular}

$2^{\text {nd }}$ Stage Estimation

\begin{tabular}{lccc}
\hline VARIABLES & $(1)$ & $(2)$ & $(3)$ \\
process
\end{tabular}

Notes: All estimations include the same variables on firm and regional characteristics as in Table 1 , as well as sector and time fixed effects. Specifications are estimated with the random effects model. ${ }^{* * *} p<0.01,{ }^{* *} p<0.05, * p<0.1$. Robust standard errors are given in parentheses. The Simpson index is instrumented with the total number of foreign restaurants per municipality and the share of allochtoon population per municipality. 
Table 8: A Summary of Results of the Random Effects Estimations

\begin{tabular}{|c|c|c|c|}
\hline Variables & Innovative & Product & Process \\
\hline All firms & \multicolumn{3}{|c|}{ Sign of the predicted coefficient } \\
\hline Co-location index & $(-)^{* * *}$ & $(-)^{* * *}$ & $(-)$ \\
\hline Unique number of birthplaces & $(+)$ & $(+)$ & $(+)^{* * *}$ \\
\hline Simpson index & $(-)^{*}$ & $(-)$ & $(-)$ \\
\hline Firms with international markets orientation ${ }^{a}$ & \multicolumn{3}{|c|}{ Sign of the predicted coefficient } \\
\hline Co-location index & $(-)^{*}$ & $(-)^{* *}$ & $(-)$ \\
\hline Unique number of birthplaces & $(+)^{* *}$ & $(+)$ & $(+)^{* * *}$ \\
\hline Simpson index & $(-)^{* *}$ & $(-)$ & $(-)$ \\
\hline Firms with domestic markets orientation $^{a}$ & \multicolumn{3}{|c|}{ Sign of the predicted coefficient } \\
\hline Co-location index & $(-)^{* * *}$ & $(-)^{* * *}$ & $(-)$ \\
\hline Unique number of birthplaces & $(+)$ & $(+)$ & $(+)^{* * *}$ \\
\hline Simpson index & $(-)^{*}$ & $(-)$ & $(-)$ \\
\hline $\begin{array}{l}\text { Sub-sample of sectors with highest } \\
\text { percentage of low-skilled workers excluded }\end{array}$ & \multicolumn{3}{|c|}{ Sign of the predicted coefficient } \\
\hline Co-location index & $(-)^{* * *}$ & $(-)^{* * *}$ & $(-)$ \\
\hline Unique number of birthplaces & $(+)^{*}$ & $(+)$ & $(+)^{* * *}$ \\
\hline Simpson index & $(-)$ & $(+)$ & $(-)$ \\
\hline All firms- All diversity measures fixed at 2000 & \multicolumn{3}{|c|}{ Sign of the predicted coefficient } \\
\hline Co-location index & $(-)^{* * *}$ & $(-)^{* *}$ & $(-)$ \\
\hline Unique number of birthplaces & $(+)^{* *}$ & $(+)^{*}$ & $(+)^{* * *}$ \\
\hline Simpson index & $(-)^{* *}$ & $(-)^{*}$ & $(-)$ \\
\hline Instrumental Variables Estimation & \multicolumn{3}{|c|}{ Sign of the predicted coefficient } \\
\hline Co-location index & $(-)^{* * *}$ & $(-)^{* * *}$ & $(-)$ \\
\hline Unique number of birthplaces & $(+)$ & $(+)$ & $(+)^{* * *}$ \\
\hline Simpson index & $(-)$ & $(-)$ & $(+)$ \\
\hline
\end{tabular}

Notes: ${ }^{a}$ Markets that the firms produce are derived from the responses to the question: "In which geographic markets did

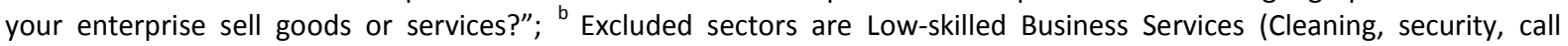
centres, secretaries, photography developers etc), Retail Trade, Hotels and Restaurants, and Manufacturing n.e.c (Furniture, Recycling n.e.c. etc). (+) and (-) signs indicate the sign of the estimated coefficients. ${ }^{* * *} p<0.01, * * p<0.05, *$ $\mathrm{p}<0.1$. 